\title{
Differences between Journals and Years in the Proportions of Students, Researchers and Faculty Registering Mendeley Articles $^{1}$
}

Mike Thelwall, Statistical Cybermetrics Research Group, University of Wolverhampton, UK.

This article contains two investigations into Mendeley reader counts with the same dataset. Mendeley reader counts provide evidence of early scholarly impact for journal articles, but reflect the reading of a relatively young subset of all researchers. To investigate whether this age bias is constant or varies by narrow field and publication year, this article compares the proportions of student, researcher and faculty readers for articles published 1996-2016 in 36 large monodisciplinary journals. In these journals, undergraduates recorded the newest research and faculty the oldest, with large differences between journals. The existence of substantial differences in the composition of readers between related fields points to the need for caution when using Mendeley readers as substitutes for citations for broad fields. The second investigation shows, with the same data, that there are substantial differences between narrow fields in the time taken for Scopus citations to be as numerous as Mendeley readers. Thus, even narrow field differences can impact on the relative value of Mendeley compared to citation counts.

\section{Introduction}

Citation counts are routinely used by governments, institutions, departments and individuals to support formal or informal research impact evaluations (e.g., Wouters \& Costas, 2012). In general, highly cited articles are more likely to have made a valuable contribution to scholarship than less cited articles of the same age and field (Merton, 1973). The value of citation counts is limited for recent research, however, since it takes several years for an article to attract a substantial number of citations (Abramo, Cicero, \& D'Angelo, 2011; Priem, Taraborelli, Groth, \& Neylon, 2010). This is unfortunate given that the newest research is most relevant for research evaluation. One solution is to use reader counts from the online reference manager Mendeley (Gunn, 2013) instead since these appear more quickly. A scholar might add an article to their Mendeley library when they first read it, years in advance of their research being written up, submitted, published and indexed by Scopus or the Web of Science (WoS). Although articles might be added to Mendeley by people that have not read them, most users add articles because they have read them or intend to read them (Mohammadi, Thelwall, \& Kousha, 2016) and therefore Mendeley gives an indicator of readership, at least for people that use the site. Mendeley readers are more common than other social media metrics except perhaps tweets (Haustein, Larivière, Thelwall, Amyot, \& Peters, 2014; Zahedi, Costas, \& Wouters, 2014) and have a high correlation with citation counts in the long term (Costas, Zahedi, \& Wouters, 2015; Li, Thelwall, \& Giustini, 2011; Thelwall \& Wilson, 2016; Zahedi, Costas, \& Wouters, 2014) as well as with human judgements (HEFCE, 2015). They are thus an attractive data source for early impact assessments.

A problem with Mendeley readership counts is that they incorporate a range of biases that limit their uses for some types of evaluations. They have indirect international

\footnotetext{
${ }^{1}$ Thelwall, M. (in press). Differences between journals and years in the proportions of students, researchers and faculty registering Mendeley articles. Scientometrics. doi:10.1007/s11192-018-2689-7
} 
biases because people tend to read articles written by authors from their own country (Thelwall \& Maflahi, 2015) and the uptake of Mendeley varies by country. Mendeley data cannot therefore be used to compare nations, unless compensating steps are taken (Fairclough \& Thelwall, 2015). It is also biased towards articles read by younger researchers (Mohammadi, Thelwall, Haustein, \& Larivière, 2015), although it is not clear whether this biases any types of research evaluation in practice.

An important difference between Mendeley reader data and citations is that the former includes non-publishing academics, such as students. Moreover, Mendeley reports the proportion of readers for a document by academic status and so it is possible to compare different reader categories. From this data, PhD students and postdoctoral researchers are numerically dominant in Mendeley, although faculty and students also register articles in the site (Mohammadi, Thelwall, Haustein, \& Larivière, 2015). It is not known how these groups of readers vary in the age of the publications read, however, which would be useful to give deeper insights into seniority-related biases within Mendeley statistics. Students are sometimes assigned books or journal articles for reading, although the extent to which this occurs varies by discipline and level (e.g., Dinkelman, 2010; Williams, Cody, \& Parnell, 2004). It seems likely that recent papers would be less easy to understand for undergraduates in hierarchical subjects, such as mathematics and natural sciences.

An unrelated issue is that Mendeley readership change their relationship with citation counts over time. When they first appear in Scopus, few articles have any citations at all but if they have long publication backlogs, then most may already have Mendeley readers (Maflahi \& Thelwall, 2018; Thelwall, 2017b). Mendeley readers accumulate about a year before Scopus citations for four library and information science journals (Maflahi \& Thelwall, 2016: data from April 2014, years 1996-2013 analysed). This is also true when analysing articles from entire countries (Fairclough \& Thelwall, 2015). The same conclusion was found for five broad categories and their subfields, but there were disciplinary differences between categories and minor differences between subfields (Thelwall \& Sud, 2016: years 2004-2014 for agriculture, business, decision science, pharmacy, and the social sciences and 50 subcategories, data from November - December 2014). It is not clear whether the differences between subfields are due to the presence of generalist journals within narrow categories, however. Moreover, the extent to which fields can differ from each other is partly obscured by the combination of journals within a single category. This article also did not explicitly identify how long it took for Scopus citations to equal Mendeley reader counts.

Despite the above findings, the extent to which the relationship between Scopus citation counts and Mendeley readership counts differs between narrow fields is not clear, and nothing is known about whether there are temporal differences in reader seniority that would cause complex biases. These are important omissions because for most citation analysis purposes, journals are clustered together into subject categories and so if the relationship differs for similar journals then this would undermine the value of Mendeley reader counts. This article addresses these two different issues in a single paper since they can be addressed with the same recycled dataset and partly overlapping methods. It uses journals as proxies for narrow fields, with the following research questions. For the first question, the focus is on the time when average Mendeley reader counts and average Scopus citation counts are the same because, other factors being equal, higher average scores give more statistical power (e.g., for correlations: Thelwall, 2016b). 
- RQ1: How substantial are the differences between narrow fields in the time taken for Scopus citations to be as numerous as Mendeley readers?

- RQ2: How does the average age of articles read vary by the academic status of Mendeley readers?

\section{Methods}

The research design for the first research question is to compare the Mendeley readership counts with the Scopus citation counts of large monodisciplinary journals for articles published at different points in time, identifying their crossing points (i.e., when Scopus citations equal Mendeley readers). Large journals were chosen to give more powerful statistical evidence. Monodisciplinary journals are effective proxies for fields because journal editors and referees ensure that articles published fall within the journal's defined scope. This is more effective than the subject categories of citation indexes, which are designed for information retrieval rather than citation analysis. For the second research question, the research design is to compare the average age of articles read by different classes of reader in the same 36 journals.

\section{Data}

A set of monodisciplinary journals was reused from a previous paper. This was taken from the 50 Scopus journals with the most articles published in 1996 and that published continually since then, ensuring long term coverage. The start date of 1996 reflects the year when Scopus expanded in coverage. General journals, such as PLOS ONE, were removed to retain only monodisciplinary publications. Mendeley reader counts were collected for the current paper to add to this data set. Both DOls and metadata searches were used to match Scopus articles to Mendeley records, combining the results to give the most comprehensive data (Zahedi, Haustein, \& Bowman, 2014). Many of the older articles in some journals did not have DOIs and so all articles without DOIs were discarded to give fairer comparisons over time.

The Scopus citations were collected in February-March 2017 and the Mendeley readers were collected April-May 2017. The Mendeley readers therefore have an advantage of 2 extra months over the Scopus citations.

Articles with a Mendeley reader count of 0 could be genuine zeros (no Mendeley readers) or artificial zeros (Mendeley readers, but the article not found by the Mendeley API searches used). For this study, all zeros were assumed to be genuine, and kept in the analysis, since there is no practical method to differentiate between the two types. This assumption is important for the first research question because readers that cannot be found in Mendeley are of no practical value for research evaluation.

\section{Scopus vs. Mendeley}

Average citation and reader counts were calculated for each journal and year using geometric means (Zitt, 2012). Since reader counts are highly skewed (Thelwall \& Wilson, 2016), the arithmetic mean is inappropriate (Thelwall, 2016a). For this calculation, the counts were first log-transformed with the formula $\ln (1+x)$, then the arithmetic mean was calculated and the result transformed back with $\exp (x)-1$. For each journal and year, 95\% confidence intervals were calculated using the t-distribution formula on the logtransformed count data, which is very approximately normally distributed. 
The cross-over points between Scopus citation counts and Mendeley reader counts were identified visually from the graphs because this judgement seemed straightforward and there did not seem to be an advantage in using a mathematical approach to estimate them.

\section{Students vs. Faculty}

For the second research question, the Mendeley API was used to count the number of readers for each article by their academic status: Bachelor's degree students (i.e., undergraduates); Master's degree students; Doctoral Students (also including the PhD student category); Researchers; Faculty (including the Professor, Associate Professor, Lecturer, Senior Lecturer categories). The small Library and Other Professional categories were discarded as not relevant. The postgraduate category was discarded as ambiguous because this could encompass a variety of statuses. The same is true for the researcher category but whilst this is a natural category for postdoctoral researchers, a postgraduate would normally be a master's degree or doctoral student (or on a rarer type of degree, such as a postgraduate professional qualification) so the category has no clear interpretation.

The average age of the articles read in each journal was calculated by taking the weighted average year of the articles read. This was achieved by using the geometric mean number of readers of the given type per article in each year as the weight for the year and then averaging the years. Although it would be more natural to use the arithmetic mean readers per article instead of the geometric mean, the latter is appropriate from a statistical perspective because the data is highly skewed and safeguards against heavy use of individual articles, such as for large class assignments. It would also be more natural to use the number of articles published in each journal and each year as an additional weight but this would make comparisons between journals unfair because some have expanded more than others during 1996-2016.

For this analysis, it was important to have data from all years and so the 11 journals that did not have any Scopus records with a DOI for at least one of the years analysed were discarded for the average calculations, leaving 25.

\section{Results}

\section{Scopus vs. Mendeley}

The times when the number of Scopus citations was first equal to the number of Mendeley readers varied from mid-2007 to mid-2015 (Table 1). Since the data was gathered in the first half of 2017, the time lag varies from about 2 years to 10 years, a factor of five difference. For all journals, the trend was for Mendeley reader counts to be initially higher but lower in the long run, crossing after about 5.5 years (Figure 1 ).

As can be seen from the relative smoothness of the lines for the extreme cases of Astrophysical Journal (Figure 2) and Brain Research (Figure 3), and the relatively narrow confidence limits, the differences in time lags for the Mendeley-Scopus crossing point are clear cut and statistically significant.

The two most represented areas are physics and chemistry (Table 1). Considering only these for simplicity, and ignoring journal names specifying related areas or specialisms, both these areas have greatly differing Mendeley/Scopus crossover gaps. There is a large difference between physics-related journals, from Astrophysical Journal (2015-16) to Applied Physics Letters (2009-10). For chemistry, there is a large difference from 
Biochemistry (2009) to Journal of Organic Chemistry (2014). The differences seem to be mainly due to low uptake of Mendeley in some specialisms (e.g., astrophysics, organic chemistry), although high levels of citation in these fields may also contribute. All 36 graphs for individual journals are available at doi:10.6084/m9.figshare.5046877, together with the number of articles for each journal and year and the proportion of articles with Mendeley readers for each journal and year.

Table 1. The year at which each journal has a geometric mean number of citations approximately equal to its geometric mean number of Mendeley readers per article. Terms related to physics and chemistry are highlighted for ease of comparison.

\begin{tabular}{|c|c|c|}
\hline $\begin{array}{l}\text { Mendeley } \\
=\text { Scopus }\end{array}$ & Journal & First subject area listed in Scopus \\
\hline $2007-8$ & Brain Research & Medicine: Neurology (clinical) \\
\hline $2007-8$ & J. Neuroscience & Neuroscience \\
\hline $2008-9$ & Geophysical Research Letters & $\begin{array}{l}\text { Earth and Planetary Sciences: } \\
\text { Geophysics }\end{array}$ \\
\hline $2008-9$ & Thin Solid Films & Materials Science: Metals and Alloys \\
\hline 2009 & Biochemistry & $\begin{array}{l}\text { Biochemistry, Genetics and Molecular } \\
\text { Biology: Biochemistry }\end{array}$ \\
\hline 2009-10 & Applied Physics Letters & $\begin{array}{l}\text { Physics and Astronomy: Physics and } \\
\text { Astronomy (miscellaneous) }\end{array}$ \\
\hline $2009-10$ & $\begin{array}{l}\text { Biochemical \& Biophysical } \\
\text { Research Communications }\end{array}$ & $\begin{array}{l}\text { Biochemistry, Genetics and Molecular } \\
\text { Biology: Biophysics }\end{array}$ \\
\hline $2009-10$ & J. Chemical Physics & Physics and Astronomy \\
\hline $2009-10$ & Japanese J. Applied Physics Part 1 & Engineering \\
\hline $2009-10$ & $\begin{array}{l}\text { Langmuir (science of systems and } \\
\text { materials) }\end{array}$ & $\begin{array}{l}\text { Physics and Astronomy: Condensed } \\
\text { Matter Physics }\end{array}$ \\
\hline $2009-10$ & Physica B Condensed Matter & $\begin{array}{l}\text { Engineering: Electrical and Electronic } \\
\text { Engineering }\end{array}$ \\
\hline $2009-10$ & Physical Review A & $\begin{array}{l}\text { Physics and Astronomy: Atomic and } \\
\text { Molecular Physics, and Optics }\end{array}$ \\
\hline 2010 & J. Applied Physics & Physics and Astronomy \\
\hline 2010 & J. Biological Chemistry & $\begin{array}{l}\text { Biochemistry, Genetics and Molecular } \\
\text { Biology: Biochemistry }\end{array}$ \\
\hline 2010 & Materials Science \& Engineering A & Engineering: Mechanical Engineering \\
\hline 2010 & Physical Review Letters & Physics and Astronomy \\
\hline 2010-11 & J. Power Sources & $\begin{array}{l}\text { Energy: Energy Engineering and Power } \\
\text { Technology }\end{array}$ \\
\hline 2011 & Chemical Physics Letters & Physics and Astronomy \\
\hline 2011 & J. Immunology & $\begin{array}{l}\text { Immunology and Microbiology: } \\
\text { Immunology }\end{array}$ \\
\hline 2011 & J. Virology & Immunology and Microbiology: Virology \\
\hline 2011-12 & Applied Surface Science & $\begin{array}{l}\text { Materials Science: Surfaces, Coatings } \\
\text { and Films }\end{array}$ \\
\hline 2011-12 & $\begin{array}{l}\text { Bioorganic \& Medicinal Chemistry } \\
\text { Letters }\end{array}$ & $\begin{array}{l}\text { Pharmacology, Toxicology and } \\
\text { Pharmaceutics: Pharmaceutical Science }\end{array}$ \\
\hline
\end{tabular}




\begin{tabular}{|l|l|l|}
\hline $2011-12$ & J. American Chemical Society & Chemistry \\
\hline $2011-12$ & $\begin{array}{l}\text { Nuclear Instruments \& Methods } \\
\text { in Physics A }\end{array}$ & Physics and Astronomy: Instrumentation \\
\hline 2012 & Cancer Research & Medicine: Oncology \\
\hline 2012 & J. Agricultural \& Food Chemistry & Agricultural and Biological Sciences \\
\hline $2012-13$ & Macromolecules & Chemistry: Inorganic Chemistry \\
\hline 2013 & J. Applied Polymer Science & Materials Science: Materials Chemistry \\
\hline $2013-14$ & Inorganic Chemistry & Chemistry: Inorganic Chemistry \\
\hline $2013-14$ & $\begin{array}{l}\text { Monthly Notices of the Royal } \\
\text { Astronomical Society }\end{array}$ & $\begin{array}{l}\text { Earth and Planetary Sciences: Space and } \\
\text { Planetary Science }\end{array}$ \\
\hline $2013-14$ & Tetrahedron (organic chemistry) & Chemistry: Organic Chemistry \\
\hline $2013-14$ & $\begin{array}{l}\text { Tetrahedron Letters (organic } \\
\text { chemistry) }\end{array}$ & $\begin{array}{l}\text { Pharmacology, Toxicology and } \\
\text { Pharmaceutics: Drug Discovery }\end{array}$ \\
\hline 2014 & Astronomy \& Astrophysics & $\begin{array}{l}\text { Earth and Planetary Sciences: Space and } \\
\text { Planetary Science }\end{array}$ \\
\hline 2014 & J. Organic Chemistry & Chemistry: Organic Chemistry \\
\hline $2014-16$ & $\begin{array}{l}\text { Applied Mathematics \& } \\
\text { Computation }\end{array}$ & Mathematics: Applied Mathematics \\
\hline $2015-16$ & Astrophysical Journal & $\begin{array}{l}\text { Earth and Planetary Sciences: Space and } \\
\text { Planetary Science }\end{array}$ \\
\hline
\end{tabular}

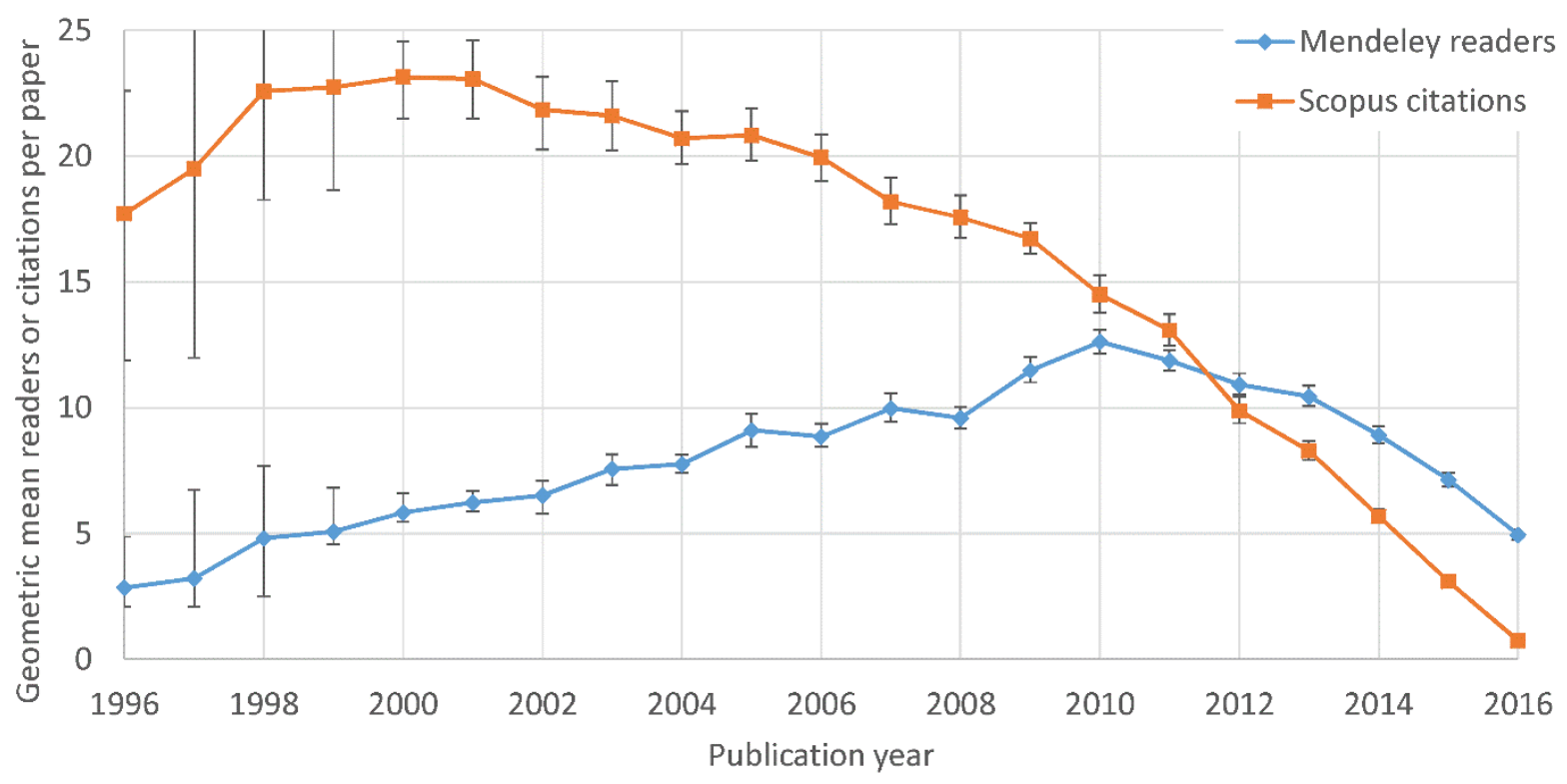

Figure 1. The median of the geometric mean Scopus citations and Mendeley readers per article across the 36 journals. Error bars reflect $95 \%$ confidence intervals calculated from tdistribution formula on the log-transformed underlying data. 


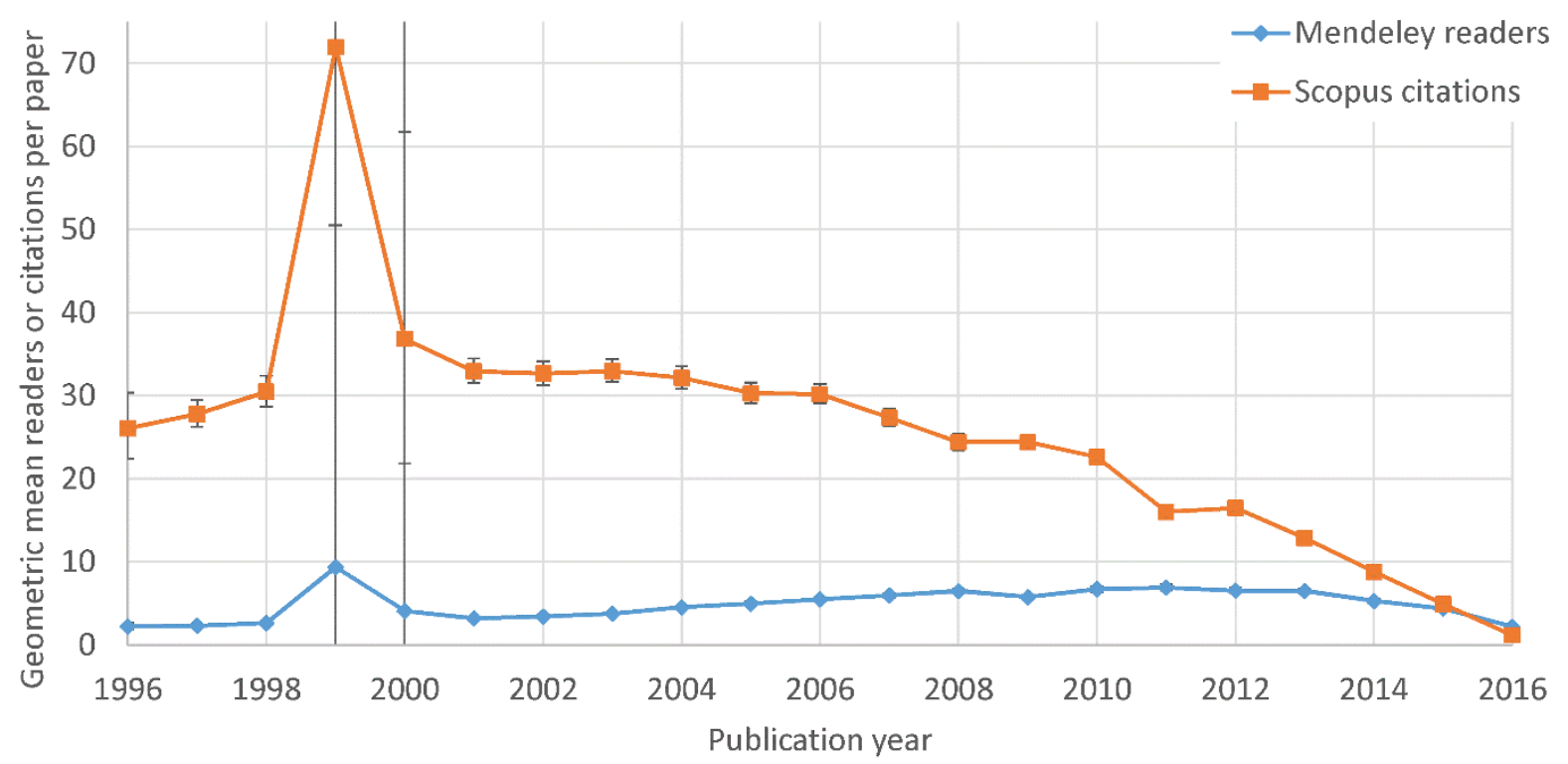

Figure 2. Geometric mean Scopus citations and Mendeley readers per article for Astrophysical Journal, which had the most recent crossover between Mendeley readers and Scopus citations. Error bars reflect $95 \%$ confidence intervals calculated from t-distribution formula on the log-transformed underlying data. The spike in 1998 and wide confidence intervals in 1998 and 1999 are a technical anomaly due to small numbers of articles having DOIs in Scopus from this journal in these two years.

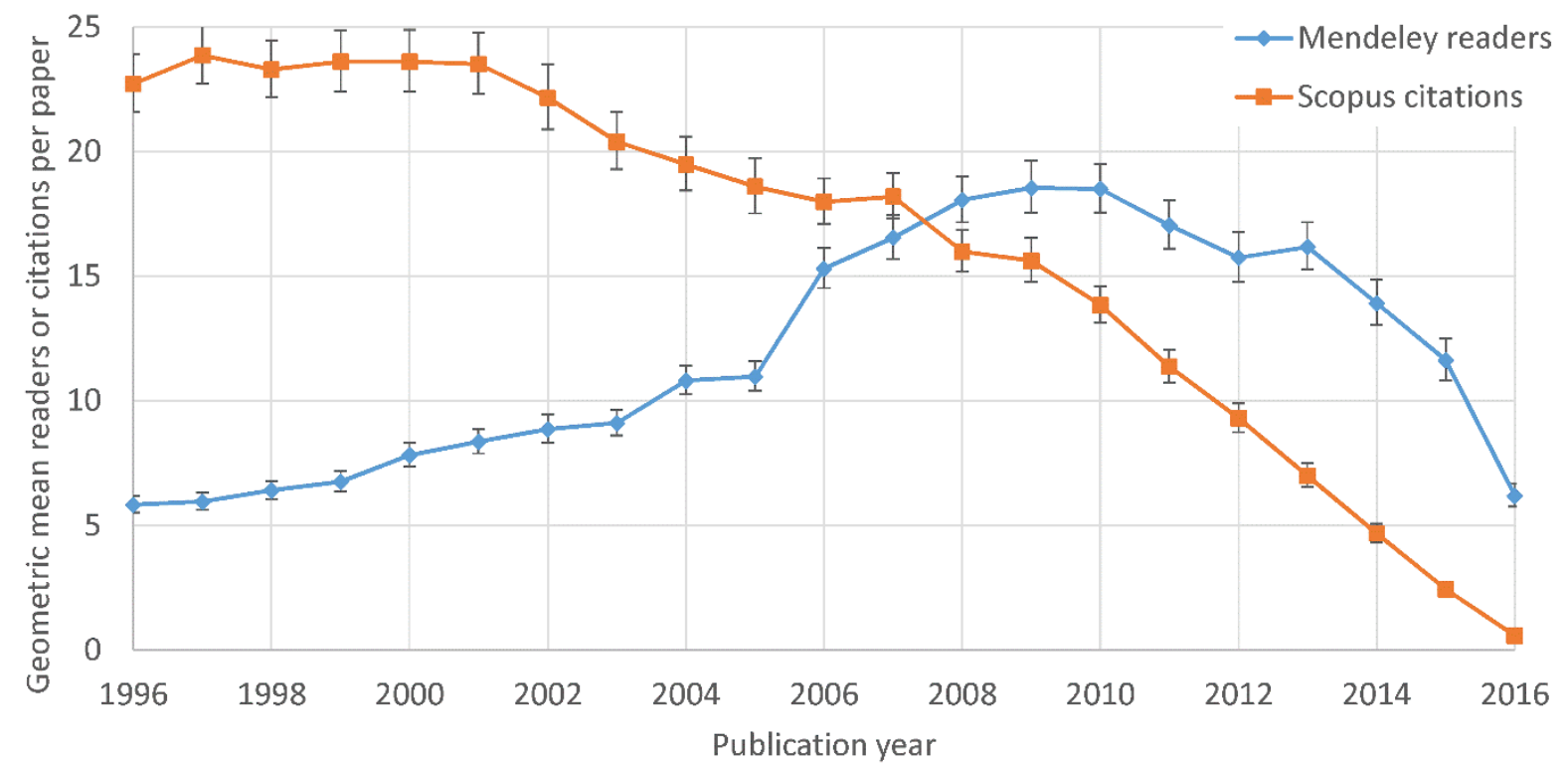

Figure 3. Geometric mean Scopus citations and Mendeley readers per article for Brain Research, which had the oldest crossover between Mendeley readers and Scopus citations. Error bars reflect $95 \%$ confidence intervals calculated from t-distribution formula on the logtransformed underlying data.

\section{Students vs. Faculty}

Undergraduates tend to register newer articles in Mendeley than faculty (as defined here, excluding researchers even if they are faculty members) for all journals. Generalising, more junior Mendeley users tend to register more recent articles than more senior users in most 
journals (Figure 4). Despite the outliers, the pattern is consistent enough for this to be accepted as a general rule, with minor exceptions.

There are also differences in the average age of articles read between journals but this is not straightforward to interpret because not all articles in all journals have been assigned a DOI and so the differences may be partly due to disciplinary differences and partly due to DOI assignment strategies for journals. Surprisingly, rapid communication journals do not stand out for having more recent articles read. For example, the average age for Tetrahedron Letters is about the same as for Tetrahedron.

It is clear from the reasonably flat line from 2000 to 2010 in Figure 5 that faculty record articles from a much wider range of years, whereas all the other groups show a peak at 2010 or after. Although other explanations are possible, interest in older articles for staff can be explained by them having read the articles before joining Mendeley and then adding the articles to Mendeley to cite them or record them for future reference. They may also have joined Mendeley before undergraduates, who are more recent additions to academia. Some of these articles may also have been published by the academics themselves, if they recorded their own CVs in Mendeley.

The biggest difference between undergraduates and faculty was for Brain Research (2.1 years, Figure 6) and the smallest was for Geophysical Research Letters ( 0.1 years, Figure 7). Brain research may be an anomaly due to a sudden change in shape in 2006 . In this year, the number of articles increased from 919 to 1374, suggesting strategic change within the journal. Geophysical Research Letters has low numbers of articles with DOls in 1996 (55), 1997 (4), 2002 (7), 2003 (84) as well as a sudden increase in 2003. All 36 graphs for individual journals are available at doi:10.6084/m9.figshare.5046877. 
J. Applied Polymer Science

Inorganic Chemistry

Bioorganic \& Medicinal Chemistry Lett.

J. Organic Chemistry

Applied Surface Science

J. American Chemical Society

Tetrahedron

Tetrahedron Letters

J. Chemical Physics

Physica B Condensed Matter

Nuclear Instruments \& Meth. Physics A

J. Applied Physics

Macromolecules

Physical Review Letters

J. Power Sources

Geophysical Research Letters

Applied Physics Letters

Langmuir

Brain Research

Chemical Physics Letters

Thin Solid Films

Astrophysical Journal

Biochemical \& Biophysical Res. Comm.

J. Biological Chemistry

Biochemistry
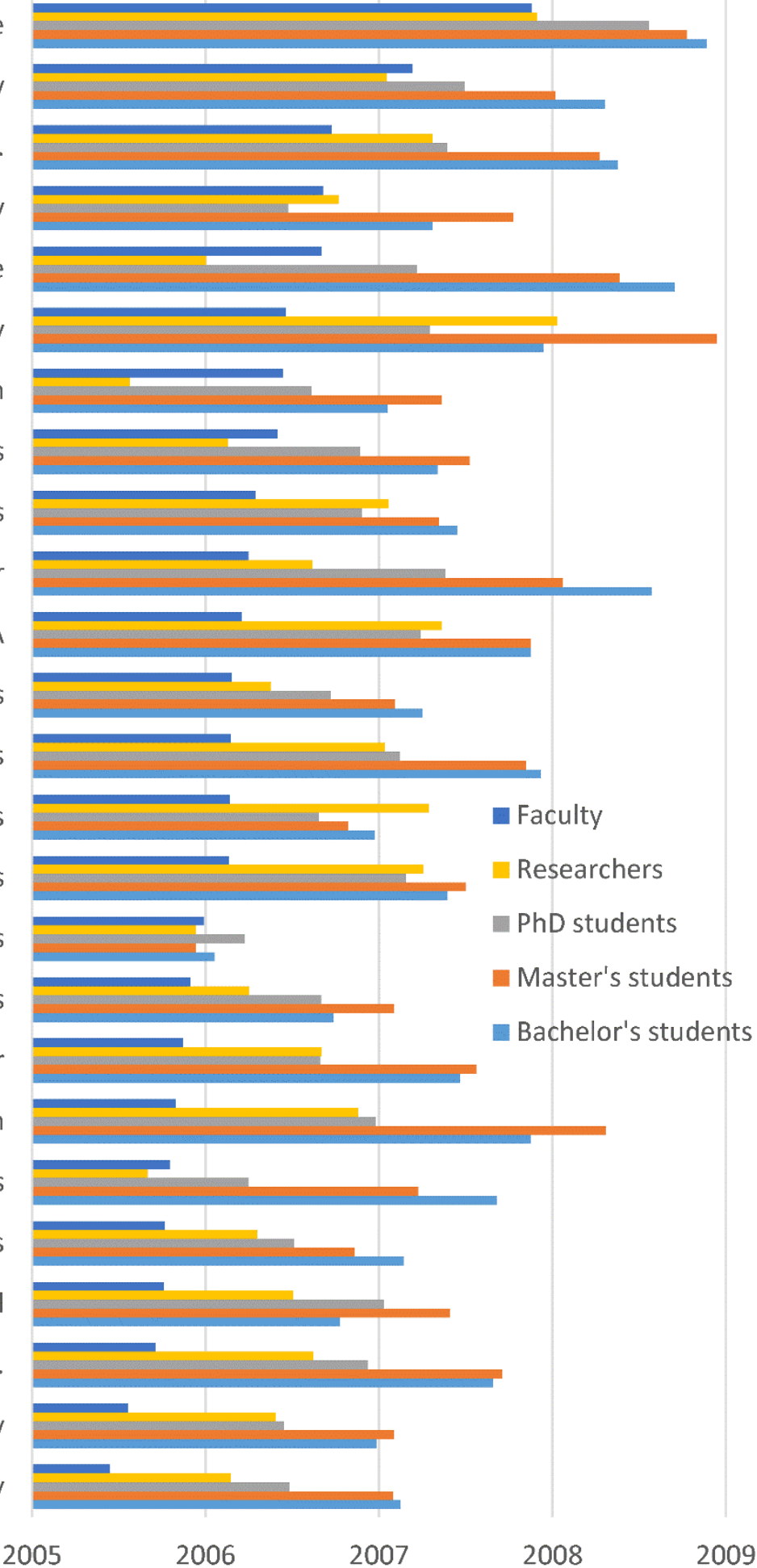

Reader-weighted geometric mean year

Figure 4. Average year of articles read by students and faculty in the 25 journals with data from all years (1996-2016). Journals are arranged in order of average age of articles read by Faculty. 


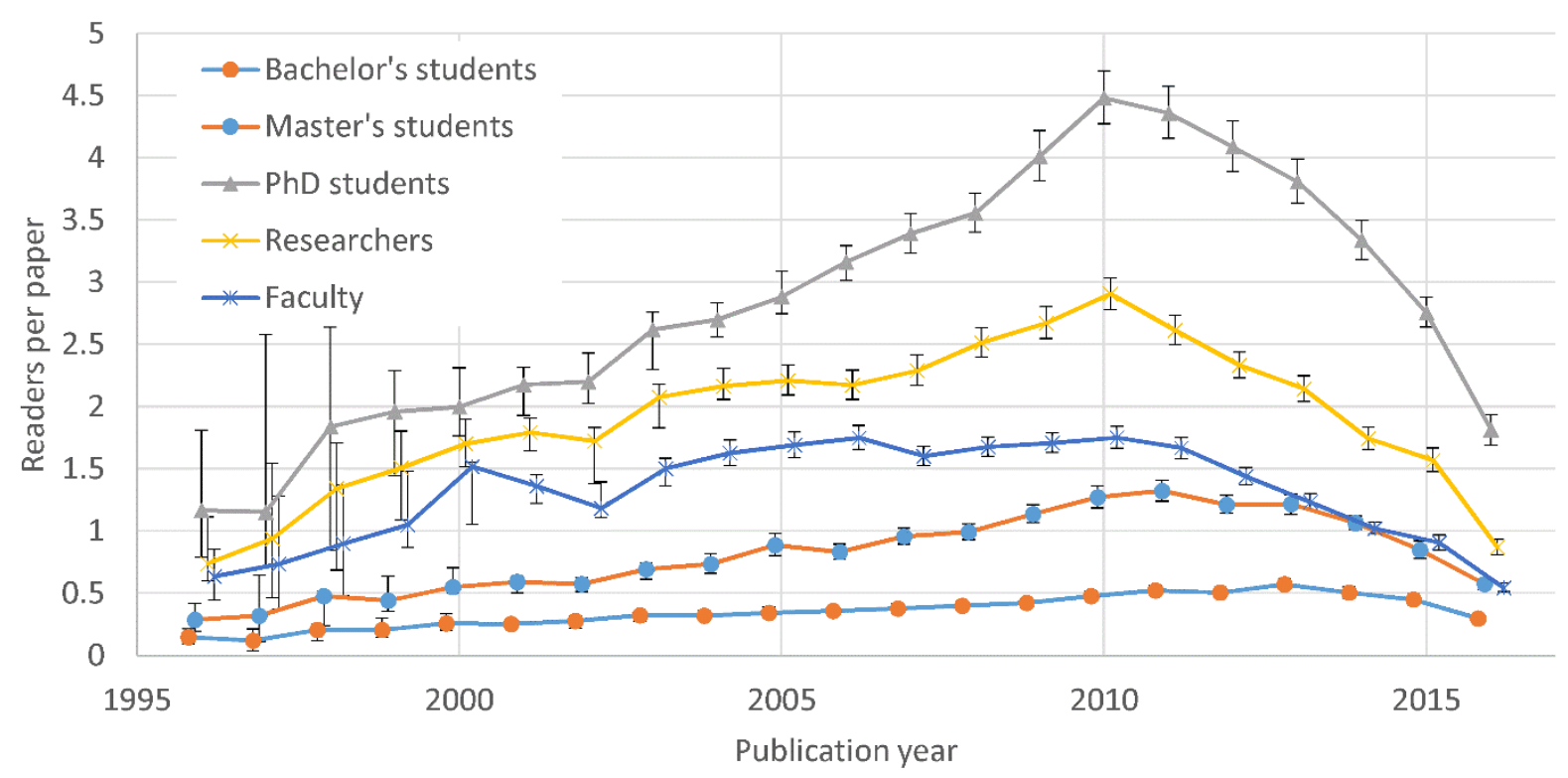

Figure 5. Geometric mean readers per article by publication year for the median of all 36 journals. Years are slightly offset so that error bars do not overlap.

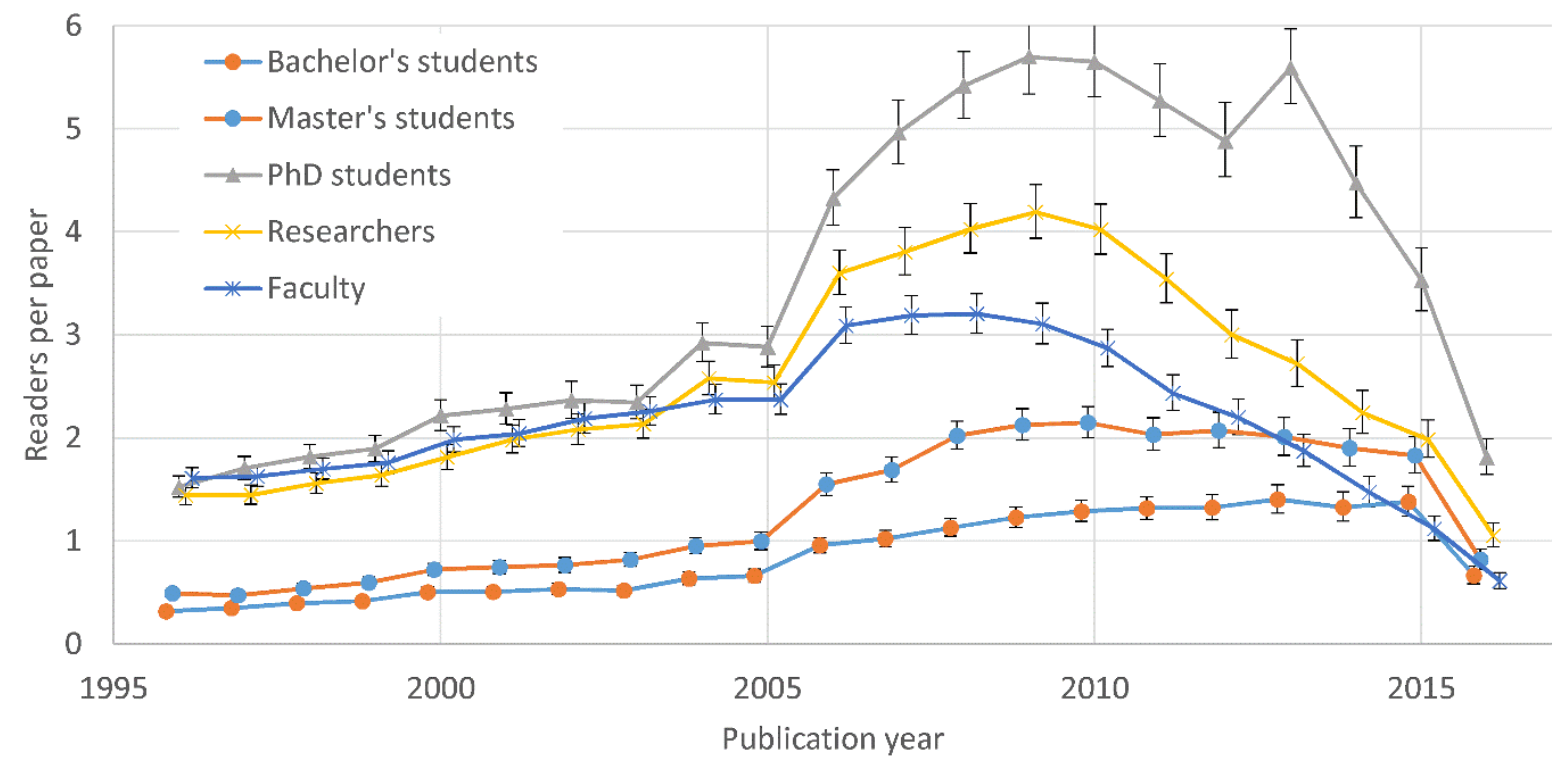

Figure 6. Geometric mean readers per article by publication year for Brain Research, with the longest faculty time lag compared to Bachelor's degree students (2.1 years). 


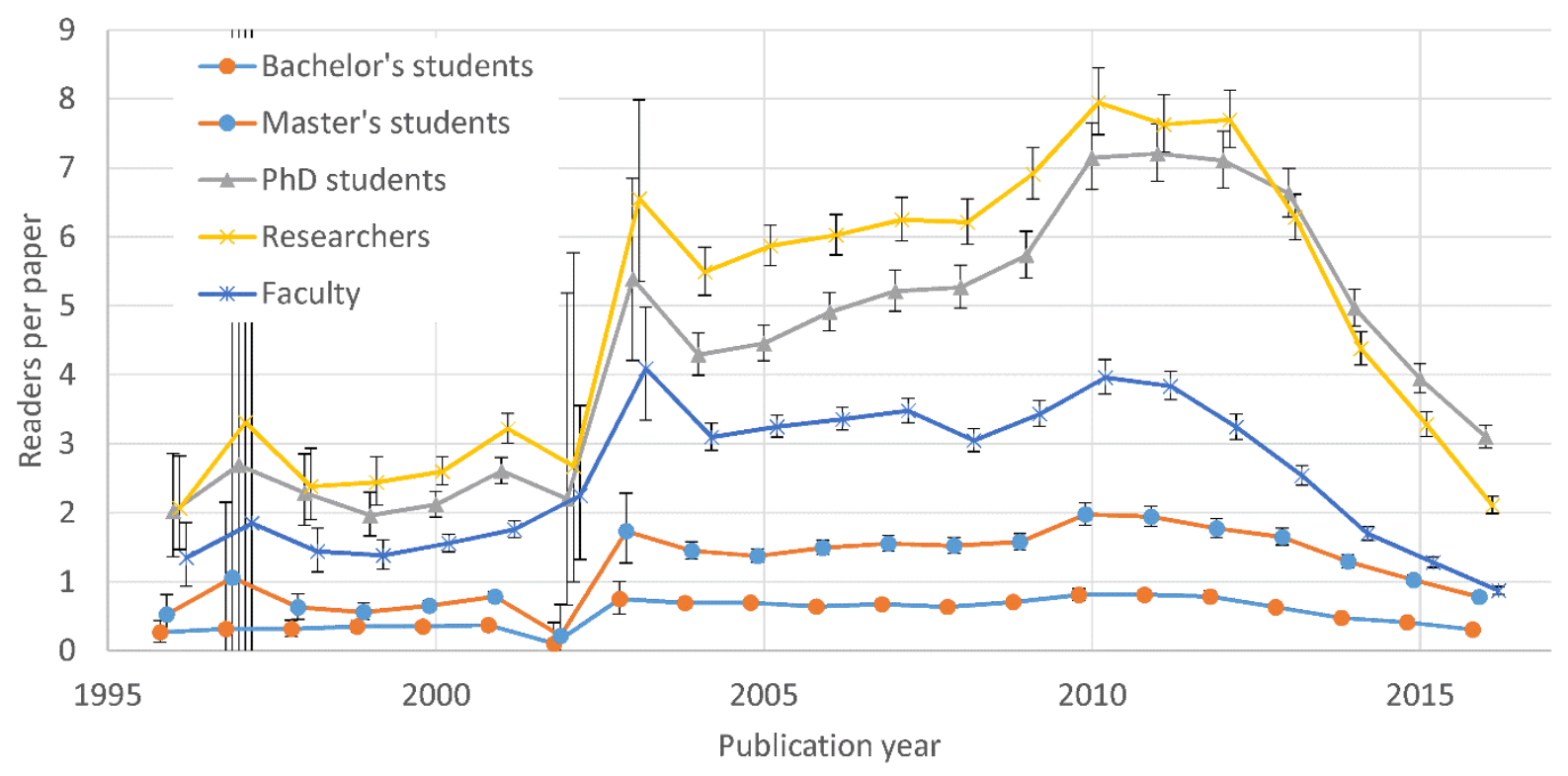

Figure 7. Geometric mean readers per article by publication year for Geophysical Research Letters, with the shortest faculty time lag compared to Bachelor's degree students $(0.4$ years).

\section{Discussion and conclusions}

The results are limited to journals from the natural sciences and medicine and so more extreme results are possible for other areas. The same is true for small specialisms that are represented by smaller journals. The occupations of readers are self-reported and may be out of date. Readers' libraries may include articles added when they were in a more junior position. They may also include articles added for training purposes rather than exclusively papers that they intend to read.

The data may be influenced by external factors that affect the uptake of Mendeley by researchers, such as its acquisition by Elsevier in 2013. Strategy changes associated with this, as well as periodic design changes and the emergence of alternative reference management strategies may also influence the number of researchers using it over time. The data is also likely to be affected by the starting year of Mendeley, 2008, since all researchers, and particularly younger researchers, are likely to mainly add recent articles and so articles before 2008 are less likely to be included. Since the number of users of Mendeley presumably grew steadily from 2008, articles in the few years after 2008 may also have a disadvantage. The data is also influenced by the proportion of articles with DOIs, since each journal introduced DOls at a given point in time, even if backdating them to earlier articles. All these factors affect the likelihood of the results from the current paper being applicable to future years.

More concretely, the Mendeley peak year of 2010 (Figure 1) has multiple partial explanations. Presumably, the average number of readers per article was not higher before 2010 because most Mendeley users had joined at least a few years after 2010 and tended to add predominantly recent articles. This might also be affected by journal DOI usage changes, however. In contrast, the average number of readers per article presumably decreased after 2010 because most Mendeley users register some articles that are older than a few years, even if most articles registered are young. Thus, if the number of active Mendeley users has been stable since 2010 and remains stable then, then peak year would stay close to 2010 . 
Moreover, excluding data from before 2010, the shape of the Mendeley graph over time (Figure 1) should broadly mimic the shape of the citation graph over time, except with an initially steeper slope. With the same assumptions, the crossing point between average Mendeley reader counts and average citation counts should remain constant at about five years before the data collection month.

The citation-related findings (RQ1) extend those of previous comparisons of Mendeley reader counts and Scopus citation counts by finding larger field differences than before. Given the wide differences within chemistry and physics, it seems likely that relatively narrow specialisms have their own citation and resource sharing cultures that sometimes exclude Mendeley (Thelwall, 2017c), perhaps because other reference sharing sites are used instead (Lee, \& Schleyer, 2012; Zoller, Doerfel, Jäschke, Stumme, \& Hotho, 2016). The low adoption of Mendeley by astrophysicists has previously been noted (Bar-Ilan, 2014). Low adoption is probably true in general for the natural sciences (Van Noorden, 2014), however, although Mendeley seems to be used to some extent in most scholarly areas (Gunn, 2013).

The current research adds the previously known national and seniority biases in Mendeley by showing that its data is unfair to narrow specialisms that rarely use Mendeley if they are analysed together with similar specialisms that use it more often. For example, this is likely to happen unless relatively narrow subject categories are used for comparison or field normalisation (Waltman, van Eck, van Leeuwen, Visser, \& van Raan, 2011ab; Thelwall, 2017a). If comparing articles from different years, the balance of junior and senior readers will be different, introducing an indirect source of unfairness. This aspect is relatively minor, however, given the low proportion of readers that are undergraduates (Mohammadi, Thelwall, Haustein, \& Larivière, 2015) and the relatively small differences found. Comparisons that involve data from both before and after DOls became standard in the journal set evaluated would present more problems because Mendeley data is more comprehensive for articles with DOIs (Zahedi, Haustein, \& Bowman, 2014) and journals may be selective in allocating DOIs to articles published before the universal adoption of DOls.

In conclusion, future research evaluation exercises that use Mendeley reader counts for early scholarly impact evidence should ensure that narrow fields are used for comparison or field normalisation purposes to avoid conflating differing biases in the proportions of readers from different groups. Results are to be interpreted with extra caution if this is not possible.

\section{References}

Abramo, G., Cicero, T., \& D’Angelo, C. A. (2011). Assessing the varying level of impact measurement accuracy as a function of the citation window length. Journal of Informetrics, 5(4), 659-667.

Bar-Ilan, J. (2014). Astrophysics publications on arXiv, Scopus and Mendeley: a case study. Scientometrics, 100(1), 217-225.

Costas, R., Zahedi, Z., \& Wouters, P. (2015). Do "altmetrics" correlate with citations? Extensive comparison of altmetric indicators with citations from a multidisciplinary perspective. Journal of the Association for Information Science and Technology, 66(10), 2003-2019.

Dinkelman, A. L. (2010). Using course syllabi to assess research expectations of biology majors: Implications for further development of information literacy skills in the 
curriculum. Issues in Science and Technology Librarianship, 60, paper 7. doi: 10.5062/F49Z92TJ

Fairclough, R. \& Thelwall, M. (2015). National research impact indicators from Mendeley readers. Journal of Informetrics, 9(4), 845-859. doi:10.1016/j.joi.2015.08.003

Gunn, W. (2013). Social signals reflect academic impact: What it means when a scholar adds a paper to Mendeley. Information standards quarterly, 25(2), 33-39.

Haustein, S., Larivière, V., Thelwall, M., Amyot, D., \& Peters, I. (2014). Tweets vs. Mendeley readers: How do these two social media metrics differ. IT-Information Technology, 56(5), 207-215.

HEFCE (2015). The Metric Tide: Correlation analysis of REF2014 scores and metrics (Supplementary Report II to the Independent Review of the Role of Metrics in Research Assessment and Management). HEFCE. DOI: 10.13140/RG.2.1.3362.4162

Lee, D. H., \& Schleyer, T. (2012). Social tagging is no substitute for controlled indexing: A comparison of Medical Subject Headings and CiteULike tags assigned to 231,388 papers. Journal of the Association for Information Science and Technology, 63(9), 1747-1757.

Li, X., Thelwall, M., \& Giustini, D. (2011). Validating online reference managers for scholarly impact measurement. Scientometrics, 91(2), 461-471.

Maflahi, N. \& Thelwall, M. (2016). When are readership counts as useful as citation counts? Scopus versus Mendeley for LIS journals. Journal of the Association for Information Science and Technology, 67(1), 191-199.

Maflahi, N, \& Thelwall, M. (2018). How quickly do publications get read? The evolution of Mendeley reader counts for new articles. Journal of the Association for Information Science and Technology, 69(1), 158-167. doi:10.1002/asi.23909

Merton, R. K. (1973). The sociology of science: Theoretical and empirical investigations. Chicago, IL: University of Chicago Press.

Mohammadi, E., Thelwall, M., Haustein, S., \& Larivière, V. (2015). Who reads research articles? An altmetrics analysis of Mendeley user categories. Journal of the Association for Information Science and Technology, 66(9), 1832-1846. doi:10.1002/asi.23286

Mohammadi, E., Thelwall, M. \& Kousha, K. (2016). Can Mendeley bookmarks reflect readership? A survey of user motivations. Journal of the Association for Information Science and Technology, 67(5), 1198-1209. doi:10.1002/asi.23477

Priem, J., Taraborelli, D., Groth, P., \& Neylon, C. (2010). Altmetrics: A manifesto. http://altmetrics.org

Thelwall, M. \& Maflahi, N. (2015). Are scholarly articles disproportionately read in their own country? An analysis of Mendeley readers. Journal of the Association for Information Science and Technology, 66(6), 1124-1135.

Thelwall, M. \& Sud, P. (2016). Mendeley readership counts: An investigation of temporal and disciplinary differences. Journal of the Association for Information Science and Technology, 57(6), 3036-3050. doi:10.1002/asi.2355

Thelwall, M. \& Wilson, P. (2016). Mendeley readership altmetrics for medical articles: An analysis of 45 fields, Journal of the Association for Information Science and Technology, 67(8), 1962-1972. doi:10.1002/asi.23501

Thelwall, M. (2016a). The precision of the arithmetic mean, geometric mean and percentiles for citation data: An experimental simulation modelling approach. Journal of Informetrics, 10(1), 110-123. doi:10.1016/j.joi.2015.12.001 
Thelwall, M. (2016b). Interpreting correlations between citation counts and other indicators. Scientometrics, 108(1), 337-347. doi:10.1007/s11192-016-1973-7

Thelwall, M. (2017a). Three practical field normalised alternative indicator formulae for research evaluation. Journal of Informetrics, 11(1), 128-151. 10.1016/j.joi.2016.12.002

Thelwall, M. (2017b). Are Mendeley reader counts high enough for research evaluations when articles are published? ASLIB Proceedings, 69(2), 174-183. doi:10.1108/AJIM-012017-0028

Thelwall, M. (2017c). Why do papers have many Mendeley readers but few Scopus-indexed citations and vice versa? Journal of Librarianship \& Information Science, 49(2), 144151. doi:10.1177/0961000615594867

Van Noorden, R. (2014). Scientists and the social network. Nature, 512(7513), 126-129.

Waltman, L., van Eck, N. J., van Leeuwen, T. N., Visser, M. S., \& van Raan, A. F. (2011a). Towards a new crown indicator: Some theoretical considerations. Journal of Informetrics, 5(1), 37-47.

Waltman, L., van Eck, N. J., van Leeuwen, T. N., Visser, M. S., \& van Raan, A. F. (2011b). Towards a new crown indicator: An empirical analysis. Scientometrics, 87(3), 467-481.

Williams, L. M., Cody, S. A., \& Parnell, J. (2004). Prospecting for new collaborations: Mining syllabi for library service opportunities. The Journal of academic librarianship, 30(4), 270-275.

Wouters, P., \& Costas, R. (2012). Users, narcissism and control: tracking the impact of scholarly publications in the 21st century. Proceedings of the 17th International Conference on Science and Technology Indicators (Vol. 2, pp. 487-497).

Zahedi, Z., Costas, R., \& Wouters, P. (2014). How well developed are altmetrics? A crossdisciplinary analysis of the presence of 'alternative metrics' in scientific publications. Scientometrics, 101(2), 1491-1513.

Zahedi, Z., Haustein, S. \& Bowman, T (2014). Exploring data quality and retrieval strategies for Mendeley reader counts. Presentation at SIGMET Metrics 2014 workshop, 5 November 2014. http://www.slideshare.net/StefanieHaustein/sigmetworkshopasist2014

Zitt, M. (2012). The journal impact factor: Angel, devil, or scapegoat? A comment on JK Vanclay's article 2011. Scientometrics, 92(2), 485-503.

Zoller, D., Doerfel, S., Jäschke, R., Stumme, G., \& Hotho, A. (2016). Posted, visited, exported: Altmetrics in the social tagging system BibSonomy. Journal of Informetrics, 10(3), 732749. 